\title{
JUURNAL.RU
}

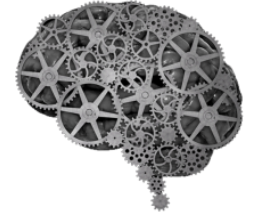

COMPANY GROUP "INTELLEKT"

\author{
Дьяконова О.С., Андреева О.В \\ ФГБОУ «Государственный университет управления» \\ Москва, Россия
}

doi: 10.18411/lj2016-5-4-03

\section{Управленческий учет в системе формирования издержек обращения в розничной торговле}

Аннотация. В статье рассматривается сущность управленческого учета издержек обращения в организациях розничной торговли. В условиях рыночной экономики торговые предприятия для достижения результативности производства внедряют систему управления хозяйственной деятельностью. Данная система управленческого учета позволяет оценить результативность производства и эффективно контролировать издержки организации.

Ключевые слова: управленческий учет,розничная торговля, издержки обращения, классификация затрат, центр ответственности.

В современных условиях рыночной экономики работа торговых предприятий требует эффективного ведения хозяйственной деятельности для получения прибыли и выживания в условиях жесткой конкуренции. В связи с этим, неизмеримо возрастает роль управленческого учета на предприятиях розничной торговли.

Управленческий учет в зарубежной теории и практике занимает достойное место, эффективность его внедрения и функционирования подтверждается той ролью, которою ему отводят многие зарубежные успешно работающие компании. За последние годы все больше российских торговых организаций используют опыт зарубежных компаний и внедряют управленческий учет, демонстрируя его эффективное функционирование. Вследствие этого, проблема 
организации эффективного управленческого учета на отечественных предприятиях является наиболее актуальной, поскольку он способствует установлению и предотвращению отрицательных результатов хозяйственной деятельности организации, а также позволяет выявить внутрихозяйственные резервы обеспечения ее финансовой устойчивости.

Научная новизна заключается в рассмотрении основных проблем организации эффективной системы управленческого учета издержек обращенияна уровне розничного торгового предприятияи разработке рекомендаций по их устранению.

Основным научно-практическим результатом статьи является разработка рекомендаций в области организации эффективности системы управленческого учета издержек обращения на предприятиях розничной торговли. Выводы и рекомендации, представленные в статье, могут быть использованы при чтении лекционных и семинарских занятий по управленческому учету.

Большую роль в управленческом учете розничной организации играет учёт издержек обращения. Как известно, издержки обращения представляют собой выраженные в денежной форме затраты труда, связанные с процессом продвижения товаров от мест производства к потребителю. Проблема учета издержек обращения является актуальной и важной проблемой политики предприятия, поскольку уровень, динамика, структура издержек взаимосвязаны со всеми сторонами хозяйственной деятельности предприятия: с вопросами планирования и организации процесса, движения товаров из сферы производства в сферу потребления.Таким образом, данная проблема приобретает особую актуальность, так как результаты работы, конкурентоспособность каждого предприятия, все больше зависят от уровня затрат.

Принятие эффективных управленческих решений во многом зависит от правильной классификации издержек обращения, что является важным в системе управленческого учета. Проанализировав экономическую литературу 
нами выделены общие признаки классификации затрат, используемые в настоящее время в практике учета управленческого анализа.В табл.1 представлена классификация затрат торговой организации в управленческом учете.

Таблицฺа 1

Классификация затрат в управленческом учете

\begin{tabular}{|c|c|}
\hline Направления управленческого учета & Классификационные признаки и группы \\
\hline Экономические элементы & $\begin{array}{l}\text {-материальные затраты; } \\
\text {-затраты на оплату труда; } \\
\text {-отчисления на социальные нужды; } \\
\text {-амортизация основных средств; } \\
\text {-прочие затраты; }\end{array}$ \\
\hline Однородность состава & $\begin{array}{l}\text {-одноэлементные; } \\
\text {-комплексные; }\end{array}$ \\
\hline Способ отнесения на себестоимость & -прямые; \\
\hline Целесообразность расходования & -производственные;-непроизводственные; \\
\hline Участие в производственном процессе & $\begin{array}{l}\text {-основные; } \\
\text {-накладные; }\end{array}$ \\
\hline Процесс учета & $\begin{array}{l}\text {-одноэлементные и комплексные; } \\
\text {-по статьям калькуляции и экономическим } \\
\text { элементам; } \\
\text {-постоянные и переменные; } \\
\text {-прямые и косвенные; } \\
\text {-основные и накладные; } \\
\text {-текущие и единовременны; }\end{array}$ \\
\hline В зависимости от объема производства & $\begin{array}{l}\text {-переменные; } \\
\text {-постоянные. }\end{array}$ \\
\hline
\end{tabular}

Приведенная выше классификация затрат в разрезе управленческих функций, повышает эффективность управленческого учета в формировании издержек обращения, позволяет усилить его аналитичность, а также выявить резервы повышения результативности деятельности торгового предприятия.

При организации системы управленческого учета издержек обращения у компании может возникать ряд проблем. Одной из таких проблем является отсутствие достаточной информации для принятия решений, а также не оперативность сбора данной информации. Для того, чтобы система учета издержек обращения приносила пользу и давала результаты необходимо обеспечение руководителей и менеджеров достоверными данными о затратах организации для принятия решений и эффективного управления предприятием. 
Данная информация об издержках обращения должна отражать все интересы пользователей, быть эффективной, полезной и поступать в максимально короткий срок. Все это необходимо для того, чтобы принимались оперативные управленческие решения, тогда можно говорить, что система управления торговой организации обеспечена конкретными показателями деятельности. Полученная информация анализируется, детализируется в соответствии с потребностями управления, и формируются с учетом задач перспективного развития организации.

Поскольку доходная составляющая торговых организаций в основном формируется за счет реализации продукции, следовательно, возникает потребность в проведении подробного анализа расходов компании и порядка организации их учета. Организация управленческого учета издержек на предприятиях розничной торговли формируется за счет использования данных экономического анализа и учета специфики издержек обращения. Анализ издержек обращения в управленческом учете устанавливает и контролирует расходы, а также помогает планировать уровень прибыли и рентабельность производства.

Исследование состава издержек обращения в торговых организациях приобретает большое значение, так как на него влияет множество факторов. Среди них выделяются внешние: экономическая ситуация в стране, условия получения кредитов и процентных ставок по ним, особенности налогового законодательства и внутренние: объем и состав товарооборота, скорость обращения товаров, уровень производительности труда работников, состояние используемых основных фондов, обеспеченность собственными оборотными активами. Учитывая влияние внешних факторов на хозяйственную деятельность, торговые предприятия должны использовать внутренние резервы для снижения торговых затрат. В первую очередь необходимо регулировать объемы закупок, сокращать затраты на транспортировку и складские помещения. 
Основной проблемой ведения управленческого учета издержек обращения является процесс распределения затрат и финансов по центрам ответственности.Каждое обособленное подразделение организации (или центр ответственности), имеет право самостоятельно принимать решение об управлении бюджетом, составлять собственную отчетность и выявлять отклонения от плановых показателей затрат. Поэтому необходимо знать, как деятельность того или иного подразделения сказывается на деятельности компании.

Следовательно, средством снижения издержек обращения, несомненно, будет являться организация их учета по центрам ответственности, что в свою очередь позволит установить персональную ответственность за определенную группу издержек обращения. Организация учета по местам возникновения затрат и центрам ответственности децентрализует управление издержками, это позволяет наблюдать за их формированием на всех уровнях управления, а также выявлять виновников непроизводительных затрат и существенно повысить экономическую эффективность хозяйствования.Таким образом, снижение издержек обращения является существенным резервом экономии средств на предприятии, это позволяет торговым компаниям выделять дополнительные средства на повышение качества обслуживания покупателей и на иные цели организации.

Немаловажную роль в снижении и оптимизации уровня издержек обращения играет степень автоматизации бизнес-процессов в торговой организации, это позволит осуществлять учет, контроль и анализ всех товарнорасчетных показателей, что в свою очередь оперативно повлияет на издержки в сторону их уменьшения.

Для повышения эффективности деятельности торговым организациям необходимо разработать и внедрить методику учета издержек обращения. Данная методика позволила бы в полном объеме использовать всю полученную бухгалтерскую и управленческую информацию. Для этого, во-первых, 
необходимо определить состав издержек обращения; во-вторых, включить в План счетов бухгалтерского учета специфические счета; в третьих, выбрать такой метод учета издержек обращения, который будет более предпочитаемым в данных условиях; в четвертых, разработать первичные документы и регистры аналитического учета издержек обращения; в пятых, выявить основную статью издержек обращения, которая способствует эффективному развитию торговой деятельности и уровню продаж. Внедрение в практику торговых компаний методики учета издержек обращения, позволит обеспечить их устойчивое и динамичное развитие.

Исходя из вышесказанного, основным показателем в системе управленческого учета торговых компаний, от которого зависит эффективность системы товародвижения, являются издержки обращения. Получение релевантной информации об издержках обращения может состояться только при полном охвате факторов, отражающих специфику деятельности организации, начиная с вида экономической деятельности, типа организации системы товародвижения, масштабы и управленческая структура бизнеса, центры ответственности, условия коммерческого расчета, система мотивации персонала, в том числе за рациональность и эффективность расходов, и многие другие факторы. Оптимизация и аккумулирование информации по данным издержкам способствует принятию эффективных оперативных и стратегических решений. Следовательно, одной из важнейших задач управленческого учета будет являться предоставление и управление информацией, которая станет основой процесса управления издержками обращения. 


\section{Литература:}

1. Блаженкова, Н. М. Влияние управленческого учета на результативность хозяйственной организации: дис. ... доктора эконом.наук : 08.00.05 / Блаженкова Н. М. - Ижевск: УГУ, 2009.- 345 с.

2. Волошин, Д. А. Анализ и оценка эффективности системы управленческого учета на предприятии:автореф. дис. ... канд. экон. наук. / Д. А. Волошин - Москва: МГУ, 2008-26 с.

3. Воронова, Е. Ю. Управленческий учет: учебник для академического бакалавриата / Е. Ю. Воронова. - 3-е изд.,переработ. и доп. - М: Издательство Юрайт, 2016. - 428 с. - Серия : Бакалавр. Академический курс.

4. Науменко, Д. В. Учет, планирование и контроль издержек производства и обращения по видам расходов / Д. В. Науменко. - М.: Лаборатория книги, 2011. - 214 c.

5. Попова, Л.В. Управленческий учет и анализ с практическими примерами: Учебное пособие // Л. В. Попова, В. А. Константинов, И. А. Маслова, Е. Ю. Степанова. М.: Дело и сервис, 2013. - 224 с.

6. Рогуленко, Т. М. Управленческий учет как инструмент управления экономическим субъектом / Т. М. Рогуленко, Д. С. Лукин // Вестник университета, серия М.- ГУУ, 2015 № 2 с. 170-176. 